\title{
Separations among Finnish Women Born between 1938-1967
}

\author{
FJALAR FINNÄS
}

Research Director

Social Science Research Unit

Åbo Akademi University

Vaasa, Finland

\begin{abstract}
The study of dissolutions in Finland until 1989 confirms corresponding findings from other countries. Consensual unions and marriages preceded by consensual unions were less stable than direct marriages. We do not interpret this as a causal relation, but rather as an outcome of a selection process. The choice of type of union is an indicator of the general attitudes and norms with respect to family formation and divorces. Furthermore, it is no longer meaningful to classify the unions according to formal marital status at the entry into the union. At present less than one union out of ten is a direct marriage, and we should instead focus on the marital status at entry into parenthood.
\end{abstract}

Keywords: dissolutions, consensual union, marriage, Finland

\section{Introduction}

According to the official vital statistics the divorce rate has increased dramatically during the most recent decades in Finland. While only about 6 percent of the marriages contracted in 1955 ended in a divorce within the first ten years of marriage, the corresponding proportion among those married in 1980 was about 16 percent. This development is not unique to Finland and can be observed in many other countries.

One probable reason for greater marital instability is that women have become more independent economically. There have also been great changes in the attitudes towards the family, marriage and cohabitation, in general. During the last decades behavior with respect to family formation has changed even more than the divorce rate. In the late 1960s cohabitation without formal marriage was still considered indecent and was rare, but twenty years later most marriages were preceded by consensual unions. There is also a trend that consensual unions achieve all the social functions of the marriages.

So far only changes in formal marital status are published in the vital statistics, and therefore these data cannot thoroughly describe the entire union formation and separation processes of today. For a deeper insight we need surveys which also consider consensual unions. In 1989 Statistics Finland conducted a survey that was comprehensive with respect to both size and content. A total of 4,155 randomly chosen women born in 1938-67 were interviewed about their entire life histories with respect to co- 
habitation, pregnancies, contraception, education, labor force participation, living conditions, and a great number of attitude questions (Nikander 1992).

A common point of departure in studies of divorces or separations during recent decades has been to study the connections between consensual unions and divorces. If a consensual union is considered to be a test period, this implies that the most suitable couples eventually marry, and thus consensual unions should lower the divorce risk. However, the empirical findings contradict this assumption, since marriages preceded by consensual unions have higher divorces rates than the other ones (Hoem and Hoem 1988; Teachman et al. 1991; Haskey 1992; Schoen 1992; Bracher et al. 1993; Ghilagaber 1993). The explanation for this is probably what the Hoems call "mode of entry self-selection", i.e., the choice between marriage and consensual union at the same time reflects the attitudes towards marriage in general. We can expect that when consensual unions were still uncommon, those who did not follow the mainstream in marriage behavior had freer attitudes towards divorce as well. At present, with consensual union the common way to start a union, direct marriage is rather an indication of an exclusive group, e.g. a religious one, which probably has stricter norms against divorce. Thus, those marrying directly have become a small selected minority, and according to Hoem and Hoem this group had a decreased divorce risk in Sweden in spite of the opposite trends in the rest of the population.

This study uses the survey data of Statistics Finland to investigate separations in more detail. The point of departure was to analyze the connections between consensual unions and divorces by taking a number of background variables into account. The methods used are intensity regression with qualitative covariates. Only the first unions of the women are studied.

The changes in family formation behavior indicate that the meaning of marriage has changed, and this causes considerable analytical problems for a divorce study. This also is true for studies of formal marriages and consensual unions. To help understand the findings, we give a brief description of the changes in family formation in Finland in the next section. We also discuss some of the analytical problems that occur. In the section on covariates we present most of the covariates and the considerations that were made about them. However, some of the covariates are not described until in the context where they are used in the last section.

\section{Family formation ${ }^{1}$ in Finland and analytical problems}

In Finland cohabitation and childbearing occurred almost exclusively in marriages until the late 1960 s. Marriages were generally preceded by an engagement period during which the couples did not cohabitate. Thus the wedding legitimated the start of cohabitation and it also indicated the start of family life that included procreation. Even though contraceptive methods were deficient, the proportion of births out of wedlock was small. In the beginning of the 1960 s only about 4 percent of all children were born to unmarried mothers. The divorce rate was also very low. In 1960 the proportions divorced of all ever-married males and females aged 50 years were 3.3 and 5.5 percent, respectively.

During the 1960 s the norms concerning family life gradually loosened. An increasing proportion of young couples moved in together without getting married. More effective contraceptive devices like IUDs and the pill allowed undesired pregnancies to be avoided more easily. At this first stage of development, consensual unions were

${ }^{1}$ This section is mainly based on published data from Statistics Finland and Finnäs (1995a) 
mainly premarriages and most couples were married at latest before the birth of the first child. The threshold for moving in together lowered, and couples started to cohabitate during their engagement period. Thus the age at entry into first union decreased somewhat. The divorce rate also started to rise slowly, and in 1970 the proportion divorced of all ever-married at the age of 50 years had increased to 4.1 percent among males and to 6.4 percent among females.

During the 1970 s behavior changed rapidly, and before 1980 about three couples out of four entered their first union without getting married. At present this is true for over nine out of ten couples. The consensual union period has also become longer. At the initial stage most couples got married at least in connection with the birth of the first child, but gradually the consensual unions became more marriage-like. This also holds for legislation, since nowadays couples with common children are treated almost equally in a legal sense, irrespective of their formal marital status. Accompanying this trend is an increase in illegitimate births. At present the proportion of births out of wedlock is almost one-third. The rise of the divorce rate has also continued, and in 1993 the proportions divorced among 50-year-old males and females were 15.8 and 17.4 percent, respectively.

The increase of the divorce rate is also clearly illustrated by the development of marriage cohorts from various yeârs (Figure 1). The most important observation in this respect is that there was a clear increase already in the marriage cohorts with no experience of consensual unions. Thus the proportion of marriages which were dissolved

F i g u re 1. The proportion of divorced by duration in Finnish marriage cohorts from varous years.

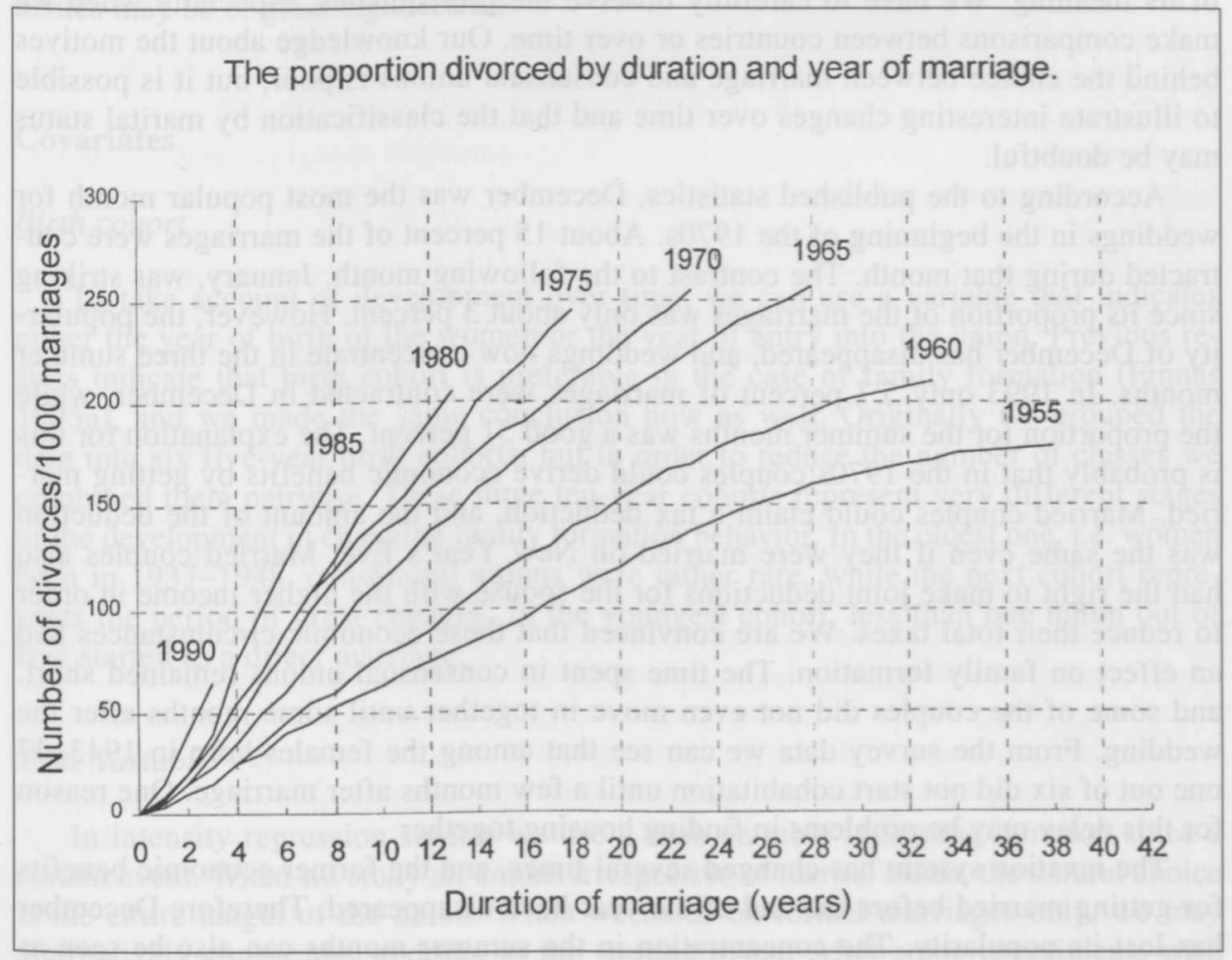

Source: Statistics Finland 
was markedly higher in the cohort from 1965 than the corresponding proportion from the 1955 and 1960 cohorts. This illustrates that most of the increase in the divorce rate cannot be ascribed to consensual unions. The changes in behavior with respect to both family formation and dissolution are probably effects of changed norms towards the family as a social institution.

One important consequence of the development is that we now have to distinguish between union formation (i.e., moving in together) and family formation, where the latter concept also includes procreation. Whereas union formation takes place at younger ages than before, family formation is postponed by about three years. Therefore we have a new stage in the life cycle, a period of childless cohabitation (most often as unmarried). Previously this period was very short.

When we analyze the effects of consensual unions, it is very important to observe these great changes and also to recognize at what stage of the changing process the population is. At least in the Nordic countries, there has been no stable stage in the sense that behavior would remained unchanged for several years. Instead, the characteristic feature of development is a rapid and continuous transition from a stage almost without consensual unions to one where almost every marriage is preceded by a period of informal cohabitation. However, the Nordic countries differ with respect to the timing of the changes. Sweden and Denmark can be considered forerunners. A rough estimate is that in the late 1980s Sweden lay about ten years ahead of Finland, while Norway was another five years behind. In Sweden consensual unions were common already in the 1941-45 cohort. Two out of three first unions were consensual unions, and in the 1951-55 cohort the proportion was about 90 percent. In Finland the corresponding proportions were one-tenth and two-thirds, respectively.

Technically it is straightforward to classify unions by formal marital status. However, the use of a covariate indicating marital status can be problematic due to the change of its meaning. We have to carefully observe the prerequisites, especially when we make comparisons between countries or over time. Our knowledge about the motives behind the choice between marriage and consensual unions is poor, but it is possible to illustrate interesting changes over time and that the classification by marital status may be doubtful.

According to the published statistics, December was the most popular month for weddings in the beginning of the 1970s. About 15 percent of the marriages were contracted during that month. The contrast to the following month, January, was striking since its proportion of the marriages was only about 3 percent. However, the popularity of December has disappeared, and weddings now concentrate in the three summer months. In 1993 only 5.7 percent of marriages were contracted in December, while the proportion for the summer months was a good 51 percent. The explanation for this is probably that in the 1970 s couples could derive economic benefits by getting married. Married couples could claim a tax deduction, and the amount of the deduction was the same even if they were married on New Year's Eve. Married couples also had the right to make joint deductions for the spouse with the higher income in order to reduce their total taxes. We are convinced that these economic circumstances had an effect on family formation. The time spent in consensual unions remained short, and some of the couples did not even move in together until some months after the wedding. From the survey data we can see that among the females born in 1943-47 one out of six did not start cohabitation until a few months after marriage. One reason for this delay may be problems in finding housing together.

The taxation system has changed several times, and the former economic benefits for getting married before the end of the year have disappeared. Therefore December has lost its popularity. The concentration in the summer months can also be seen as an indication that the wedding, to an even greater degree than before, is a very festive 
occasion for relatives and friends, and much less a prerequisite for a respectable way to be.

One conclusion from these findings is that we must be critical of a strict classification by formal marital status, especially at the entry into first union. The precise order of the events of moving in together and getting married cannot be decisive if they are very close in time. This is especially true when the norms had started to loosen. In some introductory investigations we also found that the behavior of those who got married after only a few months in a consensual union was very much the same as that of people who were married directly. A short consensual union can hardly be considered a test marriage and in many cases the date of the wedding was probably set before the entry into the union. Consequently we have considered those who married within six months as directly married in this study.

Consensual unions also cause other problems. No matter what definition we use, the meaning of the observation unit has changed. In present-day Finland it is not enough to study formal marriages and divorces only. On the other hand, the social meaning of the young couple in a consensual union today is not the same as that of marriage in the 1970s. The new stage as a childless unmarried couple in a consensual union is perhaps more comparable with the former engagement period.

Turning to Figure 1, we should mention another problem, although it is of minor importance in this study. Until 1987 divorces were permitted in court on certain grounds, such as infidelity, alcoholism, or mental disease. The amendment of the Marriage Act in 1988 made the process much easier, since the divorce is not handled in court and no particular reasons have to be stated. The effect of this change was an immediate increase in the divorce rate, which also can be observed in Figure 1. Since the Finnish survey was performed in 1989 , the effect of this change is very small in this study, and it is irrelevant for the consensual unions. However, this kind of changing prerequisites may be of great significance.

\section{Covariates}

\section{Birth cohort}

To take account of development over time, we can use a variable that indicates either the year of birth of the women or the year of entry into the union. Previous results indicate that birth cohort is preferable in the case of family formation (Finnäs 1995a), and we made the same conclusion now as well. Originally we grouped the data into six five-year birth cohorts, but in order to reduce the number of classes we combined them pairwise. These three ten-year cohorts represent very different stages of the development in changing family formation behavior. In the oldest one, i.e. women born in 1937-1948, consensual unions were rather rare, while the next cohort represents the period of great changes. In the youngest cohort, less than one union out of five started as a direct marriage.

\section{Time variable}

In intensity regression studies we use a time variable indicating duration since a certain event. When we study all unions irrespective of marital status, the natural choice is the entire length of the union. When we focus on formal marriages only, we may alternatively choose the wedding as the starting event. After some experiments with both of these alternatives, we decided to use length of the marriage when we study 
formal marriages. However, to take account of the total length of the union we also included an additional variable indicating the length of a preceding consensual union.

All dates are given to the closest month. Originally the duration variable was grouped into one-year intervals up to 8 years and two-year intervals up to 20 years. However, these intervals were combined later on. The variable that expresses the length of a preceding consensual union has three classes, namely 0-6 months, 7-23 months and over 24 months.

\section{Age}

In many studies of divorces, age at marriage has proved to be one of the most important explanatory variables. Since we do not focus on formal marriages only, we have used a variable which more generally indicates the age at the start of the observation period, i.e. entry into the union or marriage. Hoem (1995) has shown that a conventional age grouping may give misleading results with respect to education levels. The reason for this is that fixed age groupings cannot catch the social meaning of age for women at different levels of education. Hoem studied third-birth fertility, but her arguments are relevant in the present case as well, and therefore we have used different age groups for the various levels of education. In either case we used three age categories, low, medium and high and the limits were as follows:

\begin{tabular}{llll} 
Level of education & \multicolumn{3}{c}{ Age } \\
Low & Low & Medium & High \\
Medium & -18 years & $19-20$ years & $21+$ years \\
High & -19 years & $20-21$ years & $22+$ years \\
& -22 years & $23-25$ years & $26+$ years
\end{tabular}

The choice of age group categories was determined by size. That is, for each level of education we tried to classify the women into three groups of equal size.

\section{Level of education}

During the period of study there has also been a dramatic rise in the level of education in Finland. Among the women born in 1938-42, almost half remained without any further education than the compulsory one, and only about one-tenth have reached the academic level. The proportion remaining without education has diminished and among those born in 1963-67 it was less then ten percent. At the same time the proportion with an academic education has doubled.

Family formation behavior differs dramatically among the various levels of education and the effect is different for men and women. Men with a high level of education seem to be attractive on the marriage market, while it seems difficult for women to combine a high education and family life. In 1970 the proportion unmarried among 45-54-year-old women with a high level of education was as high as 27 percent, while the corresponding figure for those at the low level was only 11 percent. Among the men the proportions were 3 and 13 percent respectively. As the level of education has increased, these differences seem to have leveled off somewhat. This is especially true for the women. Apparently this is partly due to the freer cohabitation forms, since women who get a high education have started to cohabitate at younger ages. However, women with a high level of education are evidently more conservative with respect to their family formation behavior, and among them very few remain unmarried after the birth of the first child. 
In a previous study of the divorce rate in Finland based on an extensive longitudinal data file, it appeared that level of education was an important covariate (Finnäs 1995b). For both sexes the divorce rate decreased with an increase of level of education. The variable used is a time covariate and expresses the level of an achieved or ongoing education. As usual the women were grouped into three classes, low, medium and high, where the medium level corresponds to an education of 10-12 years, i.e., 1-3 years after comprehensive school.

\section{Number of children}

The arrival of a common child can be seen as an indication that the spouses get on very well and, speaking in the economic terms of Becker(1974), common children are a "marital specific capital" that will keep the union together. Thus, women with children are expected to have lower divorce risks than childless women. In consensual unions the birth of a child also signals the transition to a more marriage-like stage. In this study we use a variable that measures the number of children born within the union. However, in most cases we have only distinguished between women with and without children.

\section{Religious activity}

Considering the attitudes of the Lutheran church and various religious movements towards sexuality, marriage, and divorce, it seems natural to assume that the religiosity of a person should have an effect on the divorce risk. We have seen that consensual unions are less common among religiously active people, and we now assume that the same is true for divorces as well.

Our classification of the women is based on a question about how often they attend religious meetings disregarding weddings, funerals, baptisms and the like. We used only two groups: an active and a passive one. To be considered as active a woman had to attend religious meetings at least twice a month. With this criterion about one-tenth were classified into the active group. Due to increasing secularization, this proportion decreases dramatically in succeeding cohorts. Whereas about 16 percent were religiously active among women born in 1938-42, the proportion was only 6 percent among those born 1963-67. To some extent this may depend on the fact that the question relates to the present situation, not a certain age.

\section{Region and degree of urbanization}

The study by Finnäs (1995b) was limited to only three of the twelve provinces in Finland, but between these there were clear differences. In the province of Uusimaa the divorce risk was almost double that of the province of Vaasa. Furthermore, it was shown that the divorce risk increased with an increasing degree of urbanization of the place of residence. One reason for the great regional differences was assumed to be the high frequency of revival movements in the province of Vaasa. The effect of urbanization was explained in terms of social integration. The higher the degree of urbanization, the weaker social control and social support are, which results in marital instability.

We have included these variables in this study as well. We divided the country into four regions, southern (province of Uusimaa), western (Ahvenanmaa, Turku and Pori, and Häme), eastern (Kymi, Mikkeli, Pohjois-Karjala and Kuopio) and northern (Vaasa, Keski-Suomi, Oulu and Lappi). 
The measure for degree of urbanization expresses the proportion of the population that lives in densely built-up areas. We have used three groups rural, medium and urban, with the limits $0-39$ percent, $40-79$ percent and over 80 percent, respectively. Both region and degree of urbanization are time-varying covariates, but the classification of the municipalities with respect to degree of urbanization refers to the situation in 1980.

\section{Findings}

In order to get an overview of the general development, we first fitted a simple model for all unions irrespective of formal marital status using only duration and birth cohort as explanatory variables. Table 1 shows that when the consensual unions are included, the rise of the dissolution risk is even bigger than in Figure 1. According to this model the proportion of dissolved unions after ten years was about 10 percent in the oldest cohort but it had risen to almost 50 percent in the youngest one. Since very few of the women in the youngest cohort can be studied more than about five years, the latter figure has to be interpreted with caution.

Already these findings indicate that the consensual unions must be less stable than the marriages, and this is very evident in Table 2, where marital status is included in the model. In this case marital status is a time-covariate than combines the actual status and the status at entry into the union. Thus the variable has three classes, directly married, married after a period in a consensual union, and still in a consensual union. The dissolution risk has been more than four times as high among women in consensual unions as compared to directly married ones. The calculated proportions of dissolved unions after ten years for the directly married women were 9.5 and 23.8 percent in the oldest and youngest cohorts, respectively. The corresponding proportions for those in consensual unions were 35.3 and 69.3 percent. These calculated figures illustrate the very big difference between the two forms of unions, but it is important to realize that for the unmarried women the figures must not be considered as estimates of the total proportion of dissolved unions after ten years among those who entered consensual unions. The calculation is conditional on remaining unmarried. As seen from Table 2 those who were married after a period in a consensual union do not differ very much from the directly married ones. We will return to this question later on.

One interesting finding is that the interaction between birth cohort and marital status did not significantly improve the fit of the model, which means that the rise of the dissolution risk was about the same in all the various groups. In Sweden the directly married women showed a decrease, apparently due to an increased selection into that group.

$\mathrm{T}$ a b l e 1. Relative dissolution risks for Finnish women born 1938-67. All unions regardless of formal marital status.

Duration (months since entry into first union)

$\begin{array}{llllllll}0-11 & 12-23 & 24-35 & 36-47 & 48-71 & 72-95 & 96-119 & 120- \\ 1.0 & 1.20 & 1.58 & 1.67 & 1.12 & 1.02 & 0.90 & 1.01\end{array}$

Cohort

$\begin{array}{llllll}1938-42 & 1943-47 & 1948-52 & 1953-57 & 1958-62 & 1963-67 \\ 1.0 & 1.31 & 1.66 & 1.95 & 2.96 & 5.72 \\ \left(10.8^{*}\right) & (14.0) & (17.3) & (20.1) & (28.8) & (48.1)\end{array}$

- The numbers within the parentheses are the estimated proportion of dissolved unions after 10 years. 
T a b l e 2. Relative dissolution risks for Finnish women born 1938-67. All unions by marital status.

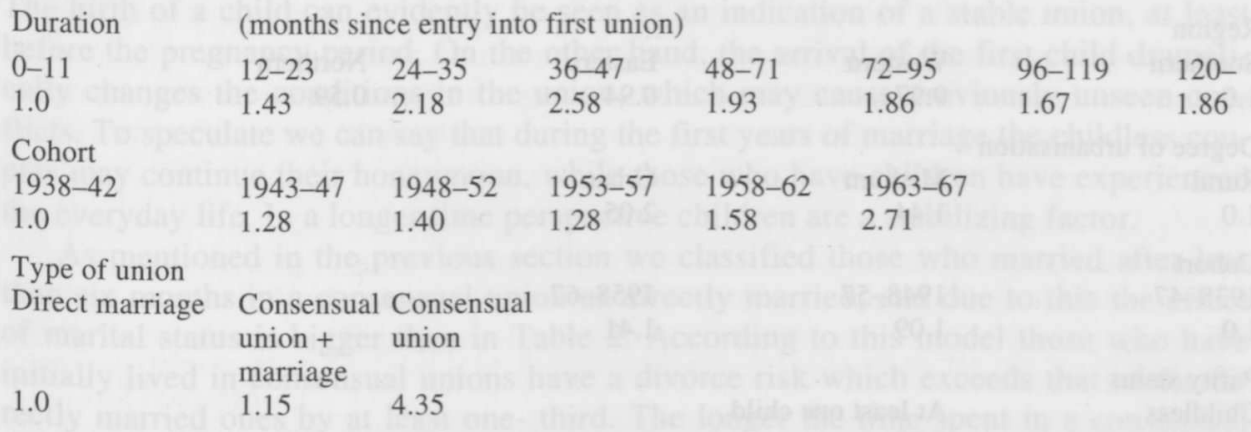

We argued that in the formation stage it is important to distinguish between unions and families. The same is evidently true for dissolutions as well. In order to focus on the families only, we eliminated the childless women, and used age of the oldest child as the time variable. The results are very much the same as before, with a very high dissolution risk in consensual unions (Table 3).

T a b l e 3. Relative dissolution risks for Finnish women born 1937-68 by duration since the birth of the first child.

\begin{tabular}{|c|c|c|c|c|c|c|c|}
\hline Duration & (months sinc & ce the birth & $f$ the first & ild) & & & \\
\hline $0-11$ & $12-23$ & $24-35$ & $36-47$ & $48-71$ & $72-95$ & 96-119 & 120 \\
\hline 1.0 & 2.07 & 3.23 & 3.12 & 2.56 & 2.43 & 2.07 & 2.78 \\
\hline $\begin{array}{l}\text { Cohort } \\
1938-42 \\
1.0\end{array}$ & $\begin{array}{l}1943-47 \\
1.27\end{array}$ & $\begin{array}{l}1948-52 \\
1.48\end{array}$ & $\begin{array}{l}1953-57 \\
1.55\end{array}$ & $\begin{array}{l}1958-62 \\
1.53\end{array}$ & $\begin{array}{l}1963-67 \\
4.54\end{array}$ & & \\
\hline Type of union &  & & & & & & \\
\hline Direct marriage & $\begin{array}{l}\text { Consensual } \\
\text { union }+ \\
\text { marriage }\end{array}$ & $\begin{array}{l}\text { Consensual } \\
\text { union }\end{array}$ & & & & & \\
\hline 1.0 & 1.11 & 4.07 & & & & & \\
\hline
\end{tabular}

These basic findings clearly show that at least until 1989 we should not rank marriages and consensual unions as equal. An initial consensual union is not marriagelike in all respects, and even after the birth of the first child, entry into a marriage is an important signal about the nature of the union. Those who remain unmarried have a considerably higher dissolution risk. In the light of these findings and the fact that the number of women remaining in consensual unions was so limited, we decided to study married women only, when the other background variables were included.

To study the effect of the various covariates, we first fitted a model with main effects only and tested each of them. All the nine variables presented in Table 4 significantly improved the fit of the model. For the comparable variables the results are very much in concordance with those reported by Finnäs (1995b). There are considerable regional differences, and in urban areas the divorce risk is double that in rural areas. Age at marriage is decisive and the divorce risk for those marrying young is very high as compared to the others. A high level of education clearly reduces the divorce risk. 
$\mathrm{T}$ a b l e 4. Relative divorce risks for married women according to a model with main effects only.

$\begin{array}{ll}\begin{array}{l}\text { Region } \\ \text { Southern } \\ 1.0\end{array} & \text { Western } \\ \begin{array}{l}\text { Degree of urbanisation } \\ \text { Rural }\end{array} & 0.97 \\ 1.0 & \text { Medium } \\ \text { Cohort } & 1.44 \\ 1938-47 & \\ 1.0 & 1948-57 \\ \text { Parity status } & 1.09 \\ \text { Childless } & \\ 1.0 & \text { At least one child } \\ & 0.80\end{array}$

Duration (months since entry into marriage)

\begin{tabular}{|c|c|c|}
\hline $\begin{array}{l}0-23 \\
1.0\end{array}$ & $\begin{array}{l}24-47 \\
2.89\end{array}$ & $\begin{array}{l}48-71 \\
2.35\end{array}$ \\
\hline \multicolumn{3}{|c|}{ Length of consensual union (Before the marriage) } \\
\hline $\begin{array}{l}\text { Directly married } \\
1.0\end{array}$ & $\begin{array}{l}7-23 \text { months } \\
1.35\end{array}$ & $\begin{array}{l}24-\text { months } \\
1.53\end{array}$ \\
\hline \multicolumn{3}{|l|}{ Level of education } \\
\hline Low & Medium & High \\
\hline \multicolumn{3}{|l|}{ Religiosity } \\
\hline Active & Passive & \\
\hline 1.0 & 1.82 & \\
\hline \multicolumn{3}{|l|}{ Age at marriage } \\
\hline Low & Medium & High \\
\hline 1.0 & 0.52 & 0.35 \\
\hline
\end{tabular}

$\begin{array}{ll}\text { Eastern } & \text { Northern } \\ 0.94 & 0.59\end{array}$

Urban

2.05

$1958-67$

1.41

0.59 
until 4 years after marriage, but from that time on it is about twice that of the women with children. We think that there might be several explanations for these findings. The birth of a child can evidently be seen as an indication of a stable union, at least before the pregnancy period. On the other hand, the arrival of the first child dramatically changes the conditions in the union, which may cause previously unseen conflicts. To speculate we can say that during the first years of marriage the childless couples may continue their honeymoon, while those who have children have experienced the everyday life. In a longer time perspective children are a stabilizing factor.

As mentioned in the previous section we classified those who married after less than six months in a consensual union as directly married, and due to this the effect of marital status is bigger than in Table 2. According to this model those who have initially lived in consensual unions have a divorce risk which exceeds that of the directly married ones by at least one- third. The longer the time spent in a consensual union the higher the divorce risk.

As before, any interaction with the cohort involved did not improve the model. This implies,for example, that the increase has been almost the same for the directly married and the other women. Therefore the overall increase cannot be "explained" by the occurrence of consensual unions. We hardly believe that there are any causal connections between consensual unions and divorces. Both of these events are rather reflections of general changes in the norms and attitudes towards marriage and family life.

\section{Summary}

The present study of union dissolutions in Finland until 1989 confirms corresponding findings from other countries. Age at marriage is an important factor and the lower the age at entry into the union, the higher is the divorce rate. This holds for both consensual unions and formal marriages. Childless marriages have a higher divorce risk than the others. However, during the first years of marriage the opposite is true. This is probably due to the dramatic changes in the relationship caused by the entry into parenthood.

Religiously active persons live in more stable unions than do passive ones. The difference in the divorce risk is about one-half. This is probably due to an individual belief in life-long marriage and faithfulness for the promise of marriage. However, we also believe that it is an effect of social conditions. In a previous study several results indicate the importance of social integration. Social networks provide both support and control which help to keep families together and prohibit divorces. We believe that religiously active people are involved to a greater extent in these kinds of networks. The marked increase of the divorce risk by level of urbanization can also be interpreted in the same manner.

As expected there was a clear connection between present marital status, previous cohabiting history, and divorce risk. During the period of study, the dissolution risk in consensual unions was about four times that of the directly married unions. This holds for families with and without children. The choice of initial type of union has been an important indicator of the stability of the union, because marriages preceded by consensual unions have been less stable than direct marriages. However, we do not interpret this as a causal connection, but rather as the effect of a selection process. The choice of type of union is an indication of the general attitudes and norms with respect to family formation and divorces.

At present it is no longer meaningful to classify the unions according to marital status at the entry into the union. Ever since the beginning of the 1980s less than one- 
tenth of all new unions have been direct marriages. Now we should focus instead on the marital status at entry into parenthood. However, in our data which were compiled in 1989 , the number of unmarried mothers was still too small to make detailed analysis possible. It is not until recent years that consensual unions have become a more permanent form of living in Finland. This is very clearly reflected in the proportion of births out of wedlock. In 1988 the proportion was about 20 percent, but in 1994 it already exceeded 31 percent. With respect to consensual unions as an initial stage of family formation their development has almost reached as far as possible, but when it comes to consensual unions and children the process is still going on. It is impossible to foresee how far their development will go, but evidently the differences between the two types of unions must decrease in the future, especially since they are almost equal in a legal and economic sense. In this respect the present study is out-of-date since we are examining a period when cohabiting unmarried mothers were still rather exclusive.

One conclusion is that in a country like Finland there is hardly any motive in trying to analyze direct effects of consensual unions on the stability of the unions. We believe that the trends for family formation as well as separations reflect the same changes in society with new norms and attitudes towards family life. However, it is interesting that we are able to observe differences in the divorce rate with respect to both present marital status and previous cohabiting history. These differences indicate that the population might be categorized into various groups with different norms and attitudes. Therefore, the consensual unions as such are not essential, but they can rather be used as an indicator for such a classification. The important question is what factors determine the choice between consensual unions and formal marriages. Previously we could ask why a couple did not marry, but today we should rather be asking why some of them do, at least before the entry into parenthood. Observe that most of those who enter their first unions today have grown up during a period when most marriages have been preceded by consensual unions. For many the essential meaning of the wedding is to arrange a great party for friends and relatives. Therefore the absence of a wedding might be interpreted as a lack of this kind of strong social relations. In a previous study several results indicated that social integration has a clear effect on marital stability.

Another conclusion is that in this new situation we ought to distinguish between short and long durations of the unions. It can hardly be meaningful to compare behavior during the very first months of childless cohabitation with that of marriages with ten-year-old children. The ideal would be to study the initial stage of the family formation process separately, but in practice it is difficult to determine when a consensual union becomes a family. One possible indicator is the birth of the first child. This can also be motivated by the fact that if young childless unmarried persons separate, it most often affects only them. It is not until they have children in common that the consequences are more noticeable.

\section{References}

Becker, G. S. 1974. A theory of marriage. In : Economics of the Family, edited by T. W. Schoultz. Chicago, IL: University of Chicago Press.

Bracher, M., G. Santow, S.P. Morgan, and J. Trussell. 1993. Marriage dissolutions in Australia: models and explanations. Population Studies 47(3):403-425.

Etzler, C. 1984. Första steget i familjebildningen - Gifta sig, börja sambo eller få barn: utveckling och skillnader bland svenska kvinnor med olika social bakgrund födda 1936-60. Stockholm Research Reports in Demography No. 21. Stockholm: University of Stockholm.

Finnäs, F. 1995a. Entry into consensual unions and marriages among Finnish women born between 
1938 and 1967. Population Studies 49(1):57-70.

-. 1995b. Social integrering, heterogenitet och skilsmässor: en studie av skilsmässorisken i Svenskfinland. In: Finnäs, F.: Samboende och skilsmässor i Svenskfinland, pp. 17-42. Forskningsrapport nr 28. Vasa: Institutet för finlandssvensk samhällsforskning.

Ghilagaber, G. 1993. The Relationship Between Premarital Cohabitation and Marital Stability: Evidence for Swedish Men Born 1936-1960. Stockholm Research Reports in Demography No. 80. Stockholm: University of Stockholm.

Haskey, J. 1992. Pre-marital cohabitation and the probability of subsequent divorce: analysis using new data from the General Household Survey. Population Trends 68, HMSO: 1-10.

Hoem, B. 1995. The social meaning of the age at second birth for third-birth fertility: A methodological note on the need to sometimes respecify an intermediate variable. Paper presented at the 11 th Nordic Demographic Symposium in Helsinki 11-13.6.1995.

Hoem, B. and Hoem, J. 1988. Dissolution in Sweden: The break-up of conjugal unions to Swedish women born in 1936-60. Stockholm Research Reports in Demography No. 45. Stockholm: University of Stockholm.

Nikander, T. 1992. The Woman's Life Course and the Family Formation. Population 1992:1. Helsinki: Statistics Finland.

Schoen, R. 1992. First unions and the stability of first marriages. Journal of Marriage and the Family 54(2):281-284.

Teachman, J. D., J. Thomas, and K. Paasch, 1991. Legal status and the stability of coresidential unions. Demography 28(4):571-586.

Statistics Finland. Published data from various years. 